\title{
Propylthiouracil causes behavioral changes in rats: the role of serotonin
}

\author{
Georgeta Bocheva*, Miroslava Varadinova and Nadka Boyadjieva
}

\begin{abstract}
Address: Pharmacology and Toxicology Department, Medical Faculty, Medical University, Sofia, Bulgaria
\end{abstract}
* Corresponding author

from International Society on Brain and Behaviour: 3rd International Congress on Brain and Behaviour

Thessaloniki, Greece. 28 November - 2 December 2007

Published: 17 April 2008

Annals of General Psychiatry 2008, 7(Suppl I):S35I doi:I0.I I86/I744-859X-7-SI-S35 I

This abstract is available from: http://www.annals-general-psychiatry.com/content/7/SI/S35 I

(C) 2008 Bocheva et al.; licensee BioMed Central Ltd.

\section{Background}

Propylthiouracil is an antithyroid drug that inhibits thyroidal T4 production and peripheral conversion of T4 to T3. The manifestations of hypothyroidism are low metabolic rate, lethargy, bradycardia, sensitivity to cold and mental impairment.

The aim of this study was to determine behavior and endocrine effects after chronic application of propylthiouracil and to measure the serotonin levels in the brain of rats, pre-treated or not with 5-hydroxy-tryptophan.

\section{Materials and methods}

Male Wistar Albino rats (140 - $160 \mathrm{~g})$ were allowed free access to drinking water containing $0,02 \%$ Propylthiouracil for 5 weeks. The experimentally PTU- induced hypothyroidism was confirmed by a significant decrease of FT3 and FT4, and increase of TSH plasma levels. We performed Forced swimming test (FST) before and after 5day-treatment with 5 -hydroxy-tryptophan $(50 \mathrm{mg} / \mathrm{kg} / \mathrm{i} . \mathrm{p})$. The serotonin levels in the brain were also measured before and after 5-hydroxy-tryptophan application.

\section{Results}

The chronic exposure of Propylthiouracil leaded to alteration of rat behavior and changes in hypothalamic-pituitary-thyroid axis. A statistically important prolongation of the immobilization time was found in hypothyroid rats compared to controls. We also observed decrease of food intake and body weight. Brain serotonin levels of experimentally induced hypothyroid rats were decreased statistically significant $(0,3366+0,04829 \mathrm{~g} / \mathrm{g})$. Aftermg/g) in comparison with healthy controls $(0,8178+0,0536 \mathrm{~m} 5$ hydroxy-tryptophan treatment serotonin levels increased and depressive symptoms in rats diminished.

\section{Conclusions}

Our results indicate that PTU-induced hypothyroidism causes behavioral changes and depressive behavior in rats possibly via central serotoninergic hypofunction. Depressive symptoms could be avoided via application of serotoninergic drugs. 